\title{
A workshop on enhancing learning through technology: reflection during action and adaptation
}

\author{
Naveed Yousuf ${ }^{1}$, Azra Naseem ${ }^{2}$, Kulsoom Ghias ${ }^{3,1}$, Bushra Moiz ${ }^{4}$ \\ ${ }^{1}$ Department for Educational Development, ${ }^{2}$ Institute for Educational Development, ${ }^{3}$ Department of Biological \\ and Biomedical Sciences, ${ }^{4}$ Department of Pathology and Microbiology, Aga Khan University, Pakistan
}

Context \& reason for the idea

Many higher education institutions have embraced technology to support their teaching and learning programmes. The use of technology provides greater flexibility in learning, increases access to educational opportunities, and enhances student learning. The evidence shows that the most challenging aspect of integrating eLearning is preparation of faculty to adopt technology for enhancing student learning. Professional development workshops play a key role in keeping faculty members abreast of the new developments in technology enhanced teaching and learning $(1,2)$.

A workshop on the theme of "Enhancing Learning through Technology" was conducted in the joint Association for Excellence in Medical Education (AEME) 2013 Conference and 16 ${ }^{\text {th }}$ Aga Khan University (AKU) National Symposium after a peer-review process.

The workshop was aimed at course directors, academic leaders, course coordinators, faculty members and anyone who is engaged in or interested to teach and develop courses using technology in the higher education sector.

The objectives were:

- To recognize the need and advantages of incorporating the use of technology for teaching and learning in health professions education (HPE)

- To identify a variety of approaches around the use of technology to enhance learning in HPE

- $\quad$ To identify and use appropriate resources available to enhance teaching and learning in HPE

- To plan sessions / courses with appropriate use of technology to maximize student engagement and learning

\section{Methods}

The workshop was divided into two sessions. In the first session, interactive discussions were held on the needs and benefits of incorporating technology in HPE; various approaches to eLearning and the concepts of student learning outcomes assessment and eLearning programme evaluation. A demo of a variety of eLearning resources was given.
After the discussion session a hands-on session was held where the participants were given exposure to eLearning tools and practices

While the workshop was largely conducted as planned, several changes were made based on the workshop facilitators' reflection in action. For example, the teaching and learning strategy of the workshop was altered impromptu during the session following informal discussion with the participants to include more hands-on experience. A MOODLE shell was created and participants' in-workshop assignments were transferred to a wiki for course development. Peer and facilitator feedback were shared in real time through a discussion board. As a result, participants' needs were addressed by including hands-on practice of developing lessons/courses within theoretical models of teaching and learning with technology.

\section{Evaluation}

At the end an evaluation form was distributed to the participants to rate the various workshops attributes on a scale of 1 to 5; 1 being poor and 5 being excellent. The evaluation showed the average ratings as follows:

- $\quad$ Objectives of the activity defined: 4.0

- $\quad$ Content covered as per defined objectives: 4.2

- Presentations at the participants level of understanding: 4.6

- $\quad$ Acquired new Knowledge: 4.2

- $\quad$ Overall assessment of the activity: 4.4

Verbal feedback at the end of the workshop showed that the workshop offered the participants an opportunity to gain familiarity with a variety of approaches and technologies around the use of technology in HPE.

\section{Reference}

1. Gibson JW, Blackwell CW. Education without boundaries: Faculty Training and Support. Journal of College Teaching \& Learning. 2005;2(1):1-6.

2. Fetters ML, Duby TG. Faculty Development: A Stage Model Matched to Blended Learning Maturation. Journal of Asynchronous Learning Networks. 2011;15(1):77-86. 